P0012

\title{
TRICHROMATIC AND DICHROMATIC COLORIMETRIC ANALYSES OF THE FARNSWORTH-MUNSELL D-15 COLOR VISION TEST
}

\author{
Ali Almustanyir et al.
}

DOI 10.25039/x46.2019.PO012

from

CIE x046:2019

Proceedings

of the

29th CIE SESSION

Washington D.C., USA, June 14 - 22, 2019

(DOI 10.25039/x46.2019)

The paper has been presented at the 29th CIE Session, Washington D.C., USA, June 14-22, 2019. It has not been peer-reviewed by CIE.

(C) CIE 2019

All rights reserved. Unless otherwise specified, no part of this publication may be reproduced or utilized in any form or by any means, electronic or mechanical, including photocopying and microfilm, without permission in writing from CIE Central Bureau at the address below. Any mention of organizations or products does not imply endorsement by the CIE.

This paper is made available open access for individual use. However, in all other cases all rights are reserved unless explicit permission is sought from and given by the CIE.

CIE Central Bureau

Babenbergerstrasse 9

A-1010 Vienna

Austria

Tel.: +43 17143187

e-mail: ciecb@cie.co.at

www.cie.co.at 


\title{
TRICHROMATIC AND DICHROMATIC COLORIMETRIC ANALYSES OF THE FARNSWORTH-MUNSELL D-15 COLOR VISION TEST
}

\author{
Almustanyir, A. ${ }^{1}$, Hovis, J.K. ${ }^{2}$ \\ 1 Department of Optometry and Visual Science, King Saud University, Riyadh, KINGDOM OF \\ SAUDI ARABIA, ${ }^{2}$ School of Optometry and Vision Science, University of Waterloo, Waterloo, \\ ON, CANADA \\ jhovis@uwaterloo.ca
}

DOI 10.25039/x46.2019.PO012

\begin{abstract}
This study investigated whether transformations that provide a qualitative rendering of redgreen dichromatic vision may be used to make quantitative predictions of dichromatic colour discrimination. The Farnsworth-Munsell D15 colours were transformed into deuteranopic and protanopic CIELAB space. Multiple predicted arrangements were made based on the assumption that 1 -just noticeable difference was greater than a dichromatic $\Delta E_{a b}^{*}$ of 6 . The predicted results were compared with the results from 60 colour-normals subjects and 26 redgreen dichromats. Although the predicted arrangements using the minimum $\Delta E_{a b}^{*}$ between adjacent caps were within the range of the actual dichromat arrangements, they were not always as good as the mean values when other possible arrangements were considered. Allowing alternative arrangements when two caps may be within a JND provided a better fit to the average data and an estimate of the possible variability in actual arrangements.
\end{abstract}

Keywords: Farnsworth-Munsell D15, Predicting Dichromatic Colour Discrimination

\section{Introduction}

One of the many computer graphic tools is the ability to simulate dichromatic colour vision. These simulations allow normal trichromats to have an appreciation of how a person with a colour vision defect perceives colours. There are a number of programs available for transforming normal-coloured images into images that simulate dichromatic colour vision (Brettel et al., 1997; Capilla et al., 2004; Machado et al., 2009; Vienot et al., 1995; Vienot et al., 1999), and there are at least seven different internet sites that either simulate or provide software to simulate dichromatic vision. Of the different algorithms, Brettel et al.'s was once the most widely available because it was incorporated into the Vischeck image filters. Unfortunately, the Vischeck webpage is no longer active.

The consensus about the Brettel et al. Vischeck transformations is that they provide a reasonable first-order approximation of dichromatic colour perception, especially in terms of illustrating the potential colour confusions (Brettel et al., 1997; Vienot et al., 1995; Cole, 2004; Cole \& Harris, 2009). Nevertheless, when the dichromatic transformations were extended to predict colour-naming errors, the correlations between the dichromatic colour differences and the number of errors was only moderate (Ramaswamy \& Hovis, 2011). The reason for obtaining only a moderate success was attributed to how dichromats use brightness information to identify colours.

In this paper, we examine how well the algorithm can predict a colour-discrimination task that does not require dichromats to name colours, and there is minimal brightness information available. The selected task was the Farnsworth Munsell D15 colour vision test (D15). The D15 is frequently used to determine whether an applicant, who has a colour vision defect, has adequate colour vision discrimination to perform a job safely and efficiently. That is, the D15 is a test of adequate versus poor colour vision discrimination. The test objects are coloured caps made from various Munsell colours sampled from around the hue circle with constant chroma and value. The test avoids using colour names by instructing the patient to place the coloured cap that is most similar in appearance to the last one placed in the tray. 


\section{Methods}

\subsection{Colorimetric measurements}

The colorimetric properties of the D15 caps were measured using PR-670 Spectroradiometer (Photo Research, Syracuse, NY). An Illuminant C fluorescent lamp (X-Rite, Grand Rapids, MI) was the source. The caps were placed on a table with illuminance on the caps in the horizontal plane of 1400 lux $( \pm 5 \%)$. As recommended by the manufacturer, the photometer was turned on 15 minutes to warm up before taking any measurements. The photometer was aligned and focused on the caps. The distance from the photometer to the caps was approximately $75 \mathrm{~cm}$. The angle of the photometer with respect to the cap was approximately $45^{\circ}$. The measurement aperture diameter was $0,5^{\circ}$ with an exposure time of $10 \mathrm{msec}$. The measurement speed was normal, and each reading consisted of an average of three measurements. The measurements were repeated two more times for each cap, and the results were averaged. The light reflected from a white diffusing plate was the white reference.

\subsection{Colour differences}

The colour differences between the caps were calculated using the CIE L*a*b*(CIELAB) chromaticity space for normal and dichromat colour vision. The $L^{*}$ corresponds to brightness, $a^{*}$ corresponds to a red-green dimension, and $b^{*}$ corresponds to a blue-yellow dimension (CIE, 2007). The nonlinear CIELAB was selected over a linear transformation to facilitate comparisons with previous experiments (Ramaswamy \& Hovis, 2011). Appendix 1 shows the equations used to calculate the colour differences in normal colour space.

\subsection{Colour differences in the dichromat space}

The dichromat colour differences were calculated based on the procedure used by Ramaswamy and Hovis (2011). Note that only the red-green dichromat spaces were included in this study. Briefly, the tristimulus values were converted to $L, M$, and $S$-cone responses using Golz and Macleod (2003) equation 5. Next, the colour-normal cone responses were converted into deuteranopic and protanopic cone responses using the Brettel et al. (1997) algorithm. These cone responses were then used to calculate the dichromat tristimulus values and finally the dichromat CIELAB colour difference. Appendix 1 shows the various steps used to calculate the colour differences in dichromat space.

\subsection{Predicted Order}

The $\Delta E_{a b}^{*}$, which includes the small difference in lightness, were used to predict the possible order of the two D15 tests using a procedure that was similar to the actual test instructions. That is, the order was set so that the $\Delta E_{a b}^{*}$ between adjacent caps was minimised for each type of observer. Nevertheless, it is possible that a cap with a larger $\Delta E_{a b}^{*}$ could be a viable option because the $\Delta E_{a b}^{*}$ could be below the dichromat's threshold and so there were other possible choices for ordering. Additional predictions were carried out for these situations when the next cap had a $\Delta E_{a b}^{*}$ greater than the minimum, but less than 6 . The subsequent caps were placed based on minimum $\Delta E_{a b}^{*}$. The value of 6 was selected because the average difference between adjacent lines of confusion in dichromat space for the region where the D15 caps are located was 7. A $\Delta E_{a b}^{*}$ of 6 represents an integer value that was slightly less than the average of one just-noticeable-difference for a dichromat.

\subsection{Subjects}

Sixty subjects with normal colour vision (CVN) and 26 congenital red-green dichromats (CVD) participated in the study. They were recruited through posters, social media, posters on buses and newsletter advertisements. Colour vision was classified according to the Rayleigh colour match using the HMC Oculus anomaloscope (Oculus Optikgeräte GmbH Wetzlar, Germany). Based on the Rayleigh colour match, there were 7 deuteranopes and 19 protanopes. The mean age was $26,3(S D \pm 9,4)$ for the $C V N$ and $28,1(S D \pm 11,5)$ for the dichromats. Tinted contact lenses or spectacles were not allowed. Ocular diseases were ruled out using a short questionnaire. This study received ethics clearance through the Office of Research Ethics, at the University of Waterloo (ORE 20996). 


\subsection{Testing procedure}

All the loose caps were removed from the box and arranged randomly on the table in front of the subject. They were asked to place the coloured cap that is most similar to the previous one placed in the box. They were allowed to rearrange the caps after the caps were placed in the box. The test was administered three times without any feedback. The test was illuminated with the lamp used for the colorimetric measurements. The illuminance on the tests was at 1400 lux $( \pm 5 \%)$ in the horizontal plane. The angular subtense of the caps was $2,0^{\circ}$ at a $40 \mathrm{~cm}$ viewing distance. The test was administered 3 times without any feedback.

The D15 results were analysed by counting the number of crossings and transpositions. A major crossing was a difference between adjacent cap numbers that was greater than 2 . The results were also analysed using the Vingrys and King Smith (1988) Colour Differences Vectors analyses (CDV). The three parameters of interest were the C-index, S-index and angle. The Cindex indicates the severity of the defect and is correlated with the number of crossings. The S-index provides a measurement of how regularly the crossings are oriented. A low S-index value indicates that there is a high degree of randomness in the arrangement. The angle gives measurement as to the type of defect. All of these parameters were calculated using a custom GNU Octave program (version 4.0.0, 2015). The results of the 3 trials were averaged for further analysis.

\section{Results}

The model predicts that the CVNs should have a perfect arrangement of the caps. Ninety-two percent $(n=55)$ of the CVN did have a perfect arrangement. The remaining 5 CVNs subjects had only one transposition, which was one of the following: switching caps 1 with $2\left(\Delta E_{a b}^{*}=5,08\right), 5$ with $6\left(\Delta E_{a b}^{*}=8,15\right), 11$ with $12\left(\Delta E_{a b}^{*}=4,71\right), 13$ with $14\left(\Delta E_{a b}^{*}=5,70\right)$, and 14 with $15\left(\Delta E_{a b}^{*}=5,20\right)$.

Figures 1 and 2 show the predicted and the actual dichromat results for the protanopes and deuteranopes, respectively. The predicted results represent 63 possible arrangements for the protanope and 384 arrangements for deuteranope. The predictions using the only minimum $\Delta E_{a b}^{*}$ between adjacent caps are shown separately for comparison. In general, the mean values based on the predictions were close to, and overlapped with, the actual dichromat results for the crossings, transpositions, and the CDV parameters. Although the range of the model's angles overlapped with the deuteranopic results, the mean predicted angle and angle using the minimum $\Delta E_{a b}^{*}$ criteria were slightly more negative than the subjects' results. The mean predicted $\mathrm{S}$-indices for both deuteranope and protanope were slightly lower than the dichromat results, but the predicted $\mathrm{S}$-indices were within the range of the actual results. The predicted $\mathrm{S}$-indices using the minimum $\Delta E_{a b}^{*}$, however, were nearly the same as the dichromat results.

\section{Discussion}

This study showed that the dichromatic transformations of the D15 colours into CIELAB space provided predictions that were very similar to the actual dichromat arrangements. With the exceptions of the deuteranopic CDV angle, perhaps the number of protanopic crossings, arrangements made using the minimum $\Delta E_{a b}^{*}$ between adjacent caps were reasonably close to the mean dichromat arrangements. Allowing alternative arrangements when two caps may be within $1 \mathrm{JND}$, obviously increased the number of possible arrangements, but it also provided a slightly better fit to the average data and estimate of the variability in actual arrangements. These results provide support for using this approach to predict dichromatic colour discriminations when the colours are nearly equal in lightness. 


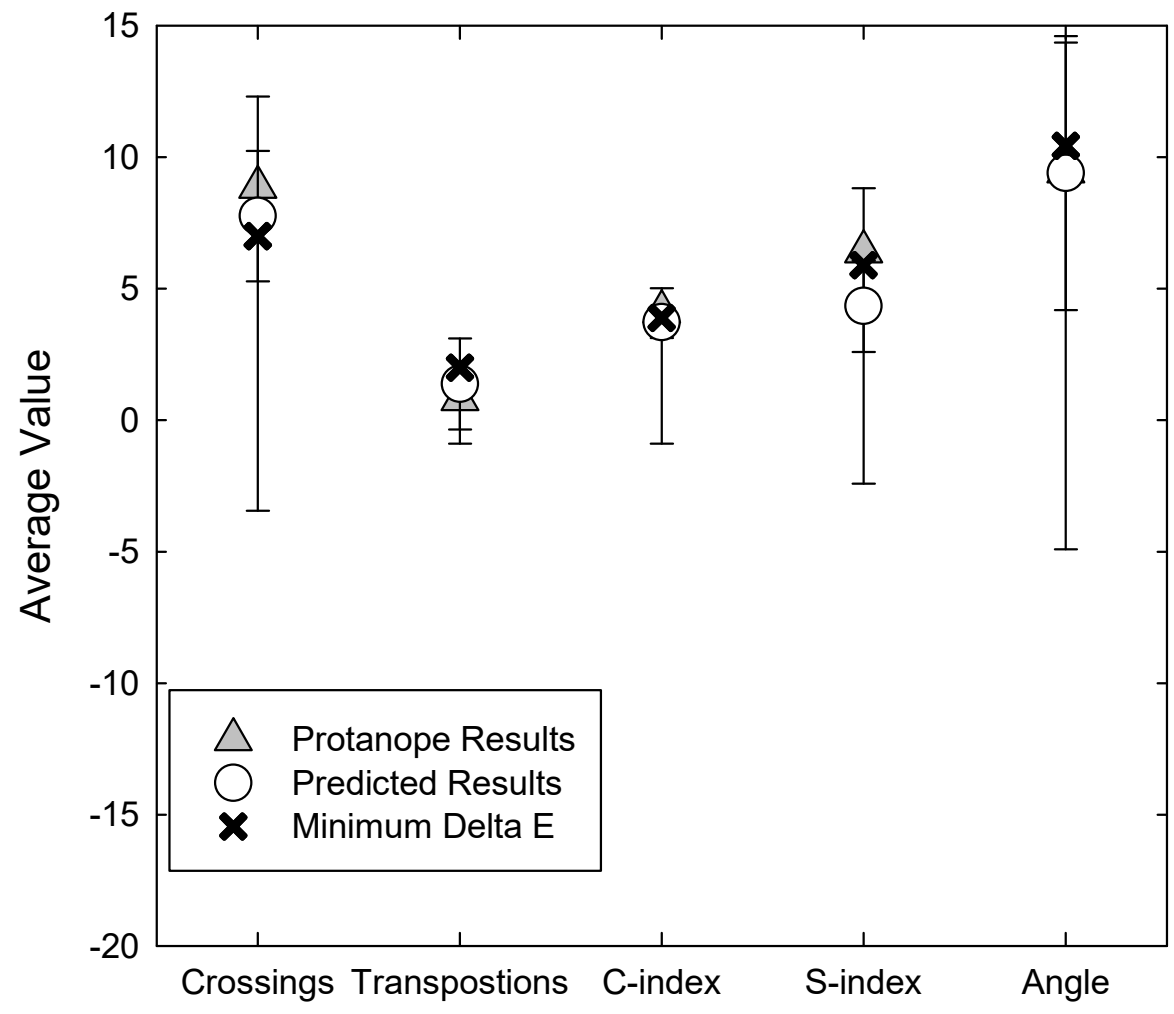

Test Results

Figure 1 - Average of the predicted (open circles) and actual protanopic arrangements (grey triangle) and the minimum $\Delta E_{a b}^{*}$ between adjacent caps arrangement (black cross). Errors bars are the \pm 2 standard deviations of the mean.

There was, however, one notable discrepancy between the model and the actual arrangements. The predicted S-index was lower than both dichromat results. The lower values indicated that predicted arrangements tended to deviate from a regular dichromat pattern and towards a more random arrangement (Vingrys \& King-Smith, 1988). This result occurred because the alternative arrangements resulted in situations where the remaining few caps had relatively large $\Delta E_{a b}^{*}$ between them and the last cap placed in the arrangement. Placing these "left-over" caps at the end resulted in irregular arrangements or mixed tritan and red-green arrangements. This type of arrangement would be similar to a patient having a few caps "leftover" that do not fit with the last one put in the box, but they cannot decide what to do with them and place them at the end in random order.

The average CVN $\Delta E_{a b}^{*}$ between the adjacent caps for the D15 was 7.3 with a range of 4.7 to 12.1. These values are generally larger than what would be considered as a small colour difference, and therefore one would expect the majority of CVN to arrange the caps correctly. This expectation was confirmed in that $92 \%$ of the CVN subjects had a perfect arrangement. If one wanted to ensure that $100 \%$ of the young adults could discriminate colours that are approximately $2^{\circ}$ and separated by a black gap of $1.5^{\circ}$, then the $\Delta E_{a b}^{*}$ should be greater than 8.0. Our model suggests that the JND value in dichromat space corresponds to a dichromat $\Delta E_{a b}^{*}$ that is greater than 6 in the respective red-green dichromat colour space. 


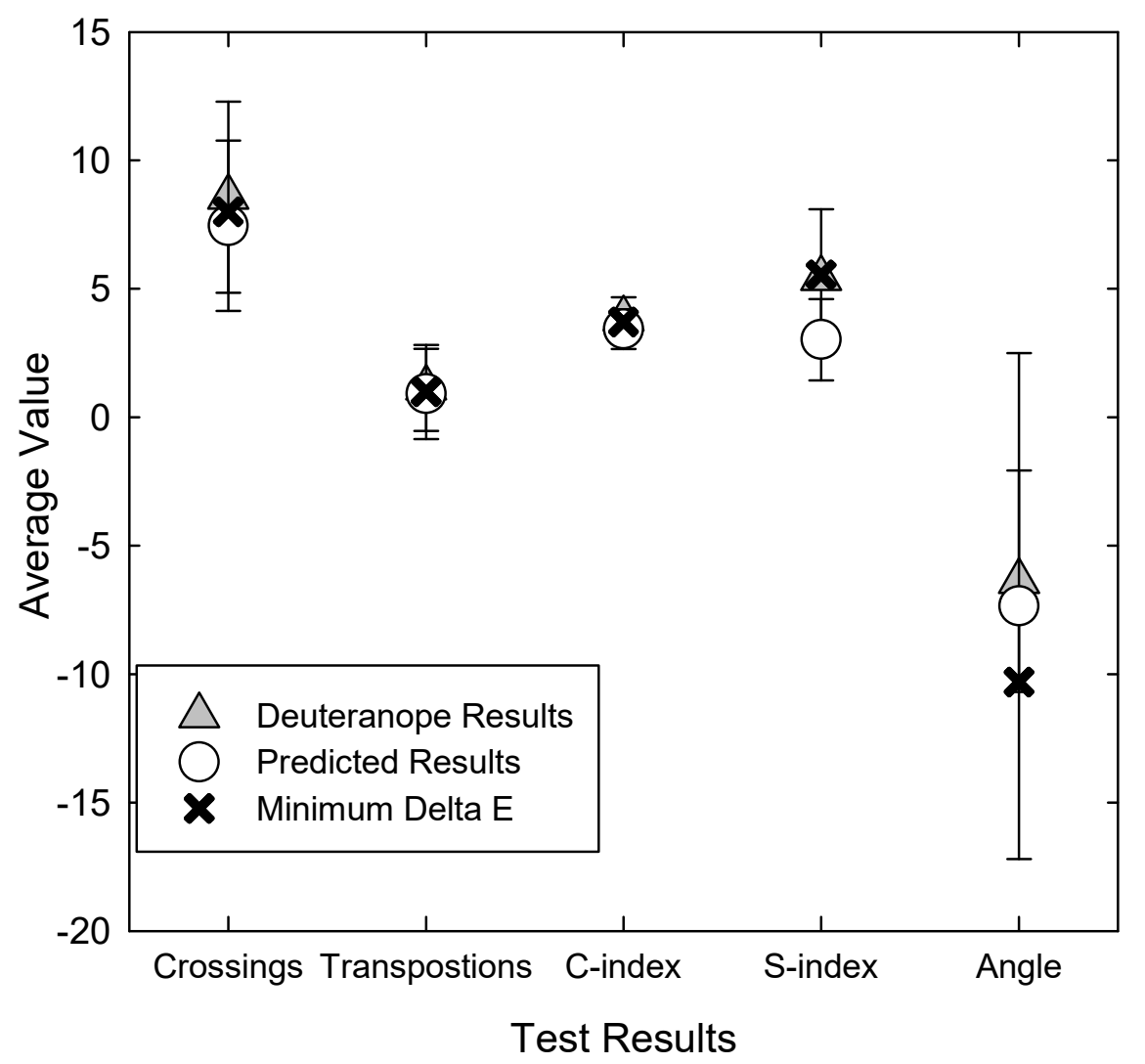

Figure 2 - Average of the predicted (open circles) and actual deuteranopic arrangements (grey triangle) and the minimum $\Delta E_{a b}^{*}$ between adjacent caps arrangement (black cross). Errors bars are the \pm 2 standard deviations of the mean.

\section{Conclusion}

Transformations that provided a qualitative rendering of red-green dichromatic vision may be used to make quantitative predictions for dichromatic colour discrimination. The transformation of the D15 cap colours into dichromatic CIELAB space provided predictions that were very similar to the actual dichromat arrangements. Although the predicted arrangements using the minimum $\Delta E_{a b}^{*}$ between adjacent caps were within the range of the actual dichromat arrangements, they were not always as good as the mean values when other possible arrangements were considered. Allowing alternative arrangements when two caps may be within a JND, obviously increased the number of possible arrangements, but it also provided a better fit to the average data and an estimate of the possible variability in actual arrangements.

\section{References}

BRETTEL, H., VIENOT, F. \& MOLLON, J. D. 1997. Computerized simulation of color appearance for dichromats. J Opt Soc Am A Opt Image Sci Vis, 14, 2647-55.

CAPILLA, P., DIEZ-AJENJO, M. A., LUQUE, M. J. \& MALO, J. 2004. Corresponding-pair procedure: a new approach to simulation of dichromatic color perception. J Opt Soc Am A Opt Image Sci Vis, 21, 176-86.

CIE 2007. CIE S 014-4/E:2007. Colorimetry — Part 4:CIE $1976 L{ }^{*} a * b *$ colour space. CIE Central Bureau, Vienna

COLE, B. L. 2004. The handicap of abnormal colour vision. Clin Exp Optom, 87, 258-75.

COLE, B. L. \& HARRIS, R. W. 2009. Colour blindness does not preclude fame as an artist: celebrated Australian artist Clifton Pugh was a protanope. Clin Exp Optom, 92, 421-8. 
GOLZ, J. \& MACLEOD, D. I. 2003. Colorimetry for CRT displays. J Opt Soc Am A Opt Image Sci Vis, 20, 769-81.

MACHADO, G. M., OLIVEIRA, M. M. \& FERNANDES, L. A. F. 2009. A Physiologically-based Model for Simulation of Color Vision Deficiency. IEEE Transactions on Visualization and Computer Graphics, 15, 1291-1298.

RAMASWAMY, S. \& HOVIS, J. K. 2011. Does dichromatic color simulation predict color identification error rates? Optom Vis Sci, 88, 621-7.

USUI, S. \& NAKAUCHI, S. 1995. Neural network models for normal and dichromatic color vision. In: DRUM, B., et al., (eds.) Colour Vision Deficiencies XII: Proceedings of the twelfth Symposium of the International Research Group on Colour Vision Deficiencies, Dordrecht: Springer Netherlands.

VIENOT, F., BRETTEL, H., OTT, L., BEN M'BAREK, A. \& MOLLON, J. D. 1995. What do colourblind people see? Nature, 376, 127-8.

VIENOT, F., BRETTEL, H. \& MOLLON, J. D. 1999. Digital video colourmaps for checking the legibility of displays by dichromats. Color Research and Application, 24, 243-252.

VINGRYS, A. J. \& KING-SMITH, P. E. 1988. A quantitative scoring technique for panel tests of color vision. Invest Ophthalmol Vis Sci, 29, 50-63.

\section{Acknowledgements}

The authors thank the College of Applied Medical Sciences Research Centre and the Deanship of Scientific Research at King Saud University for funding of this research.

\section{Appendix}

\section{A.1 Colour differences in the normal space}

In order to calculate the colour differences in CIELAB space, the chromaticity coordinates $(x, y, z)$ for each colour that has been measured were converted to tristimulus values using the following equations,

$$
\begin{aligned}
& Y=\text { Luminance }\left(\mathrm{cd} / \mathrm{m}^{2}\right) \\
& X=(Y x) / y \\
& Z=(Y z) / y
\end{aligned}
$$

where $X, Y$, and $Z$ are the tristimulus values.

The tristimulus values for each colour were converted to CIE $L^{*} a^{*} b^{*}$ space using the following equations (CIE, 2007)

$$
\begin{aligned}
& L^{*}=116(Y / Y n) \\
& a^{*}=500\left[(X / X n)^{1 / 3}-(Y / Y n)^{1 / 3}\right] \\
& b^{*}=200\left[(Y / Y n)^{1 / 3}-(\mathrm{Z} / \mathrm{Zn})^{1 / 3}\right]
\end{aligned}
$$

where $X n, Y n$, and $Z n$ are the stimulus values for the reference white. The tristimulus values of the white diffusing plate were the reference white D15.

The total colour differences between two caps were calculated using the following equation,

$$
\Delta E_{a b}^{*}=\left[\left(\Delta L^{*}\right)^{2}+\left(\Delta a^{*}\right)^{2}+\left(\Delta b^{*}\right)^{2}\right]^{1 / 2}
$$

where $\Delta L, \Delta a$, and $\Delta b$ represent the difference between the two colours coordinates. 


\section{A.2 Colour differences in the dichromatic space}

The tristimulus values were converted first to $L M S$ cone fundamental for $2^{\circ}$ field using Golz and Macleod's (2003) equation 5,

$$
\begin{aligned}
& L=0,17156 X+0,52901 Y-0,02199 Z \\
& M=-0,15955 X+0,48553 Y-0,04298 Z \\
& S=0,01916 X-0,03989 Y+1,03993 Z
\end{aligned}
$$

The next step was to convert colours into protanopic or deuteranopic cone space using Brettel et al (1997) algorithm. The colour stimuli were represented as vectors in three-dimensional in the LMS space. White stimuli for CVNs was assumed to be perceived as neutral for dichromats. The stimuli of the yellow wavelength $(575 \mathrm{~nm})$ and the blue wavelength $(475 \mathrm{~nm})$ were assumed to be same in deuteranopes and protanopes. The next section is the representation of the algorithm.

The colour stimulus in LMS space is presented as $Q$ for colour normal and as $Q$ ' for the dichromate. This colour stimulus can be projected into a plane determined by the monochromatic anchor stimulus $A$, the stimuli of the white colour $E$, and origin $O$. For a given $E$ $\left(L_{E}, M_{E}, S_{E}\right)$ and the $A\left(L_{A}, M_{A}, S_{A}\right)$, the coordinates $L_{Q^{\prime}}, M_{Q^{\prime}}, S_{Q^{\prime}}$ for a stimulus $Q^{\prime}$ can be calculated by,

$$
a L_{Q^{\prime}}+b M_{Q^{\prime}}+c S_{Q^{\prime}}=0
$$

with

$$
\begin{aligned}
& a=M_{E} \cdot S_{A}-S_{E} \cdot M_{A} \\
& b=S_{E} \cdot L_{A}-L_{E} \cdot S_{A} \\
& c=L_{E} \cdot M_{A}-M_{E} \cdot L_{A}
\end{aligned}
$$

where the $L_{A}, M_{A}$, and $S_{A}$ are the vector components of the stimulus anchor $A$ and $L_{E}, M_{E}$, and $S_{E}$ are the vector components of the white at equal energy (Brettel et al. 1997).

\section{A.2.2 Protanopic transformation}

For a given Q stimulus, the following equation is for transformation into protanopic space

$$
\begin{aligned}
& L_{Q^{\prime}}=-\left(b M_{Q}+c S_{Q}\right) / a \\
& M_{Q^{\prime}}=M_{Q} \\
& S_{Q^{\prime}}=S_{Q}
\end{aligned}
$$

If the $S_{Q} / M_{Q}<S_{E} / M_{E}$, then $\lambda_{A}=575 \mathrm{~nm}$; else $\lambda_{A}=475 \mathrm{~nm}$ (Brettel et al, 1997)

The next step was to calculate back the tristimulus values $(X, Y$, and $Z$ ) from the $L M S$ stimuli $\left(L_{Q}, M_{Q^{\prime}}, S_{Q^{\prime}}\right)$ using the inverse of (Golz, MacLeod; 2003) LMS matrix.

$$
\begin{aligned}
& X=2,892 L-3,135 M+0,191 S \\
& Y=0,952 L+1,021 M-0,022 S \\
& Z=-0,017 L+0,097 M+0,957 S
\end{aligned}
$$

The tristimulus values for each colour were converted to CIELAB space using the equations 4 , 5 , and 6 . The final step is to calculate the $\Delta E_{p a b}^{*}$ for protanopic cone space using the following equation

$$
\Delta E_{p a b}^{*}=\left[\left(\Delta L^{2}+(\Delta a)^{2}+(\Delta b)^{2}\right]^{1 / 2}\right.
$$

where $\Delta L, \Delta a$, and $\Delta b$ are the colour difference between two different colours in protanopic space. 


\section{A.2.3 Deuteranopic transformation}

For a given $Q$ stimulus, the following equations are for transformation into deuteranopic space

$$
\begin{aligned}
& L_{Q^{\prime}}=L_{Q} \\
& M_{Q^{\prime}}=-\left(a L_{Q}+c S_{Q}\right) / b \\
& S_{Q^{\prime}}=S_{Q}
\end{aligned}
$$

If the $S_{Q} / L_{Q}<S_{E} / L_{E}$, then $\lambda_{A}=575 \mathrm{~nm}$; else $\lambda_{A}=475 \mathrm{~nm}$

Next, tristimulus values $(X, Y$, and $Z)$ was calculated back using equation 15 . The tristimulus values for each colour were converted to CIELAB space using the equations 4,5 , and 6 . The final step is to calculate the $\Delta E_{d a b}^{*}$ for deuteranopic cone space using the following equation

$$
\Delta E_{d a b}^{*}=\left[(\Delta L)^{2}+(\Delta a)^{2}+(\Delta b)^{2}\right]^{1 / 2}
$$

where $\Delta L, \Delta a$, and $\Delta b$ are the colour difference between two different colours in deuteranopic space. 